\title{
The influence of the Brazilian school health program on the oral-health-related quality of life of adolescents
}

Aretuza Pires LATTANZI(a)

Ana Paula Ferreira MARQUES(a) iD

Flavia Maia SILVEIRA(b) iD

Maria Isabel Bastos VALENTE(b) iD

Lívia Azeredo ANTUNES(b) iD

Karine Laura CORTELLAZZI(c) iD

Andréa Videira ASSAF(b) iD

(a) Universidade Federal Fluminense - UFF, School of Dentistry, Postgraduate Program in Dentistry, Nova Friburgo, RJ, Brazil.

(b) Universidade Federal Fluminense - UFF, School of Dentistry, Department of Specific Formation, Nova Friburgo, RJ, Brazil.

(c) Universidade Estadual de Campinas Unicamp, School of Dentistry, Department of Public Health, Piracicaba, SP, Brazil.

Declaration of Interests: The authors certify that they have no commercial or associative interest that represents a conflict of interest in connection with the manuscript.

Corresponding Author:

Andréa Videira Assaf

E-mail: avassaf@gmail.com

Submitted: October 27, 2019

Accepted for publication: March 25, 2020

Last revision: May 26, 2020
Abstract: The aim of this study was to evaluate the influence of the Brazilian School Health Program (SHP) on dental clinical disorders such as caries, gingivitis, and dental trauma as well as on the oral-health-related quality of life (OHRQoL) of adolescents in Nova Friburgo, RJ, Brazil. The study consisted of a non-probabilistic (convenience) sample comprising 319 12-year-old adolescents, both participants and non-participants of the SHP, for at least two years. Socio-demographic and OHRQoL questionnaires $\left(\mathrm{CPQ}_{11-14}\right.$, the Child Perceptions Questionnaire) were applied as well as clinical examinations for caries, periodontal disease, and dental trauma following the World Health Organization (WHO) criteria by calibrated researchers. Mann-Whitney, chi-square tests, and multiple logistic regression models were used for the data analysis. Statistically significant differences were observed between the groups covered and not covered by the SHP for gingivitis $(p=0.0373)$ and OHRQoL on the social welfare subscale $(p=0.0265)$ and total scale $(p=0.0449)$ of $C P Q_{11-14}$. Multivariate analysis showed that female adolescents were 1.74 times more likely to present a lower OHRQoL $(\mathrm{OR}=1.74,95 \% \mathrm{IC}=1.10-2.77$, $\mathrm{p}=0.0183)$ than males. In addition, non-SHP subjects were 1.56 times more likely to have poor OHRQoL $(\mathrm{OR}=1.56,95 \% \mathrm{IC}=0.94-2.59$, $\mathrm{p}=0.0873$ ) than program participants. In conclusion, SHP positively influenced the OHRQoL of adolescents. However, follow-up studies are needed to verify the continued effectiveness of this Brazilian SHP in improving the oral health levels and quality of life of adolescents.

Keywords: Oral Health; Quality of Life; Health Promotion; Schools.

\section{Introduction}

Schools are a social tool that serve as an overview and mechanism of health education, as they help form the opinions of children, adolescents, and their families and educates citizens to be conscious and responsible for their behaviours and choices. ${ }^{1}$ As a result, school-based programs have been developed with promising results for work on self-care and health promotion. ${ }^{2}$

Within this philosophical and political social context, the School Health Program (SHP) was implemented in 2007 as part of a ministerial policy in 
Brazil intended to regulate health activities in schools by aggregating and strengthening actions from the perspective of integral development. In addition, SHP allows schoolchildren to participate in projects and programs to promote education and health in order to combat vulnerabilities that hinder the full development of Brazilian children, adolescents, and young people. ${ }^{1}$ In the area of oral health, the program aims to promote health and prevent oral diseases through oral hygiene instruction, supervised dental brushing, and guidance on healthy eating, among other activities, with the involvement of education professionals and multiprofessional teams from primary health care. ${ }^{3}$

An increased interest in the quality of life is an expected consequence of public policies for disease prevention, health promotion, and health care practices. ${ }^{24}$ Several studies have shown a relationship between clinical outcomes such as caries, trauma, and periodontal disease with oral health-related quality of life (OHRQoL) in adolescents, and the impacts of OHRQoL are mainly found in the routine, functioning, and social life of these individuals. ${ }^{5,6,7}$ However, it has also been noted that the scientific evidence on the influence of promotion programs on the OHRQoL of adolescents remains weak, as just a few studies have shown that the presence of health promotion programs involving educational-preventive interventions in oral health leads to reductions in the incidence of clinical disorders and the improvement of OHRQoL. ${ }^{8,9,10,11}$

Thus we see the importance of further research on the OHRQoL of adolescents and the impact of oral health programs on this outcome, as new studies may help decision makers to properly allocate public resources by modifying or developing improved strategies and protocols for oral health promotion for the long-term improvement of adolescents' OHRQoL and their oral health. Therefore, this study may facilitate decision-making by healthcare providers and policymakers.

Based on previous studies, ${ }^{8,9,10,11}$ the hypothesis developed by the authors of the present study concerns the effect of SHP positivity and relevance in improving oral health and OHRQoL. Thus, this investigation aimed to evaluate the influence of the
School Health Program on clinical disorders such as caries, gingivitis, and dental trauma, as well as on the quality of life related to the oral health of Brazilian adolescents.

\section{Method}

This is a cross-sectional study of a quantitative nature conducted according to the guidelines recommended by STROBE (Strengthening the Reporting of Observational Studies in Epidemiology). ${ }^{12}$

\section{Ethical statement}

The study was performed according to the Declaration of Helsinki and was approved by the Ethics and Research Committee of the Health Institute of Nova Friburgo-RJ-Brazil $(2,402,679$ CAAE: 76415817.2.0000.5626). The informed consent and free and informed consent forms were sent to the parents/guardians of the adolescents to familiarise them with the study and obtain their authorisation or refusal of the participation of the adolescents.

\section{Place of execution}

The study was carried out between March and September 2018 in the municipal and state public schools of the municipality of Nova Friburgo, in the Serrana Region of the State of Rio de Janeiro, Brazil.

The city of Nova Friburgo is located in the mountainous region of the State of Rio de Janeiro, with a total area of $933.4 \mathrm{~km}^{2}$, making up $13.46 \%$ of the mountainous area. The municipality has a population of 190,084 inhabitants with a demographic density of 195.07 (inhab $/ \mathrm{km}^{2}$ ), and the population is predominantly urban $(159,335)$. The city has 54,636 households, of which $29.0 \%$ belong to Economic Class C1, with a monthly family income of around $\mathrm{R} \$ 1,400.00$. The municipality of Nova Friburgo was classified as having a human development index (HDI) of 0.745 , ranking 4 th in the state under the HDI criterion in 2017, and had a Gini Index of 0.5153 in $2010 .{ }^{13}$ It should be noted that the public water supply in the municipality has been fluoridated since 2010 , with coverage around $80 \%$, though some rural regions remain uncovered by this measure of public health protection. ${ }^{14}$ 


\section{Study design and sample selection}

\section{Sample selection}

Our non-probabilistic sample (convenience sample) comprised 12-year-old adolescents duly enrolled in the public schools of the municipality of Nova Friburgo-RJ. First, from the lists provided by the Municipal and State Departments of Education, the municipal $(n=14)$ and state $(n=21)$ public schools with students in this age group $(n=947)$ were identified. Of these educational establishments, three with a total of 92 students that have been accredited for less than two years in the SHP were excluded from the sample, while 12 schools accredited in the program for more than two years were included in the sample, with a total of 236 students aged 12 years. It was decided to work with this population number, inviting all students not included in the SHP $(n=619)$ and those covered by the program for at least two years $(n=236)$ to participate in the study. In addition, a sample calculation was performed showing that a minimum sample size of 300 participants provided a test power of $80 \%(\beta=0.20)$ with a significance level of $10 \%(\alpha=0.10)$ for an odds ratio of 1.9 , considering that $42 \%$ of the individuals had participated in the SHP for at least 2 years and had a worse quality of life $(\mathrm{CPQ}>18)$.

\section{Eligibility criteria}

Adolescents not included in theSHP or those covered by the program for at least two years were included in the study, except those whose parents/guardians did not authorise their participation in the study, adolescents absent during the examination periods, and those who presented with a systemic impairment or cognitive deficit or who used orthodontic appliances with more than four bands.

\section{Phases of the study}

The study was conducted in two phases: a) The preparatory phase: examiner training and calibration and pilot study. b) The field phase: application of the questionnaires for socio-demographic evaluation as well as the OHRQoL of the individuals under study; clinical examination of adolescents to evaluate dental caries, dental trauma, and periodontal condition.

\section{Preparatory phase}

a. Examiner training and calibration: The calibration process of the examiners $(n=2)$ comprised a theoretical phase $(4 \mathrm{~h})$, clinical training $(8 \mathrm{~h})$, and a final phase of calibration exercises $(8 \mathrm{~h})$ to achieve examiner reproducibility. The calibration process was conducted by a researcher with previous experience in epidemiological surveys (a gold standard examiner) and lasted for 20 hours. During the field phase, $10 \%$ of the exams were repeated $(n=32)$ to allow the calculation of intra-examiner kappa.

Initially, a theoretical discussion lasting $4 \mathrm{~h}$ was carried out with a detailed explanation of the codes and criteria used, in addition to the performance of a theoretical-expository exercise based on the exhibition of photos for each clinical situation that might be encountered in the exams. Practical training then began in order to standardise the conduct and diagnosis of the clinical situations, involving the examination of 10 children in each training period under the same conditions found during the field phase. At this stage, discussions between the examiners and the standard examiner were allowed in relation to clinical findings, diagnostic criteria, coding, and registration errors so as to reach an acceptable level of agreement. The calibration assessment, incorporating agreement measures, included the examination of 10 children (re-examined after an interval of one week) under the same examination conditions and in the same environment in which the practical training was carried out. Inter- and intra-examiner Kappa values during the calibration phase and intra-examiner Kappa during the field phase were considered optimal for all evaluated oral conditions (Kappa > 0.85).

b. Pilot study: The pilot study included ten 12-year-olds at schools that were not selected for the study because they had been included in the SHP for less than 2 years before the field phase began, in order to verify the comprehensibility of the questionnaires by the adolescents and their parents/guardians as well as to review certain parameters of the epidemiological evaluations, such as the form of approach for conducting the clinical exams. 


\section{Field phase}

a. Non-clinical data collection: Assessment of the presence of the School Health Program (SHP) in the educational institutions of the adolescents participating in the study.

The Ministry of Health recommends that a large number of activities related to health promotion and disease prevention be developed interprofessionally and intersectorally in Brazilian public schools. ${ }^{1}$ In the municipality of Nova Friburgo, oral health promotion is developed by primary health care professionals through strategies such as mechanical control of dental biofilm, supervised brushing activities, and educational activities promoting a balanced and healthy diet as a central focus for the development of autonomy and self-care in oral health, among other areas, semiannually. Thus, the presence of the SHP for at least two years in the schools evaluated was considered the main independent variable for analysis.

b. Application of questionnaires: The questionnaire on sociodemographic conditions (identification, socioeconomic characterisation, and access to dental services) was based on the instrument proposed by Brazil ${ }^{15}$ and completed individually by the adolescents' guardians.

\section{Assessment of oral-health-related quality of life (OHRQOL)}

The questionnaire used to evaluate the quality of life in the interview was the Brazilian-validated long version of the $\mathrm{CPQ}_{11-14}$ (Child Perceptions Questionnaire for 11- to 14-year-old adolescents), ${ }^{16}$ which aims to evaluate adolescents' perceptions of the impact of oral diseases on physical and psychosocial functioning and which was properly applied by the researchers when the student was included in the study. The CPQ instrument consists of 41 questions divided into the following sub-items: 1-4 (questions about the child), 5-10 (questions about oral symptoms/problems), 11-19 (questions about functional limitations), 20-28 (questions about emotional well-being), 29-32 (questions about social welfare), and 32-41 (questions about free time activities and time spent with others). During the field phase, OHRQoL questionnaires were repeated in $10 \%$ of the total sample $(n=32)$ to verify the psychometric properties of the OHRQoL instrument. Satisfactory results for both internal consistency (Cronbach's $\alpha=0.926)$ and stability (ICC $=0.956)$ were obtained as well as a significant construct validity $(\mathrm{p}<0.01)$.

\section{Clinical data collection}

Clinical examination of the subjects under study for evaluation of dental caries, dental trauma, and periodontal condition.

Clinical examinations were carried out by the calibrated examiners in an outdoor setting after supervised brushing to remove biofilm and food debris under the dental surface in order to facilitate visual diagnosis. The prevalence of caries was measured using the DMFt (decayed, missing, and filled teeth) index; the periodontal condition, specifically the presence of calculus and gingivitis, was recorded using the Community Periodontal Index (CPI), and dental traumatism was evaluated according to the index adopted by the World Health Organization $(\mathrm{WHO})^{17}$ as a specific measure considering only the permanent upper and lower incisors. For dental trauma, the following types of dental trauma were collected: enamel fracture only, enamel and dentin fracture, pulp involvement, and missing tooth due to trauma. Clinical examinations were performed according to the criteria recommended by the WHO for epidemiological surveys of oral health. ${ }^{17}$

\section{Variables analysed in the study}

The following variables were considered in the analysis of possible associations:

Dependent variable-OHRQoL $\left(\mathrm{CPQ}_{11-14}\right)$, dichotomised by the median $(\mathrm{CPQ} \leq 18$ and $\mathrm{CPQ}>18)$.

Independent sociodemographic, clinical, and SHP access variables were dichotomised following Assaf et al. ${ }^{18}$ as: living in a rural or urban area, sex (female or male), $\operatorname{DMFt}(\leq 0 ;>0)$, trauma-free (yes or no), gingivitis-free (yes or no), income $(\leq 1.15$ Brazilian minimum wage [BMW] and >1.15 BMW), schooling of parents/guardians ( $\leq 8$ years of schooling and $>8$ years of schooling), and adolescents belonging to SHP in school (yes or no).

\section{Data analysis}

The descriptive analysis of the data was based on the distribution of sociodemographic variables 
and access to SHP. The Kolmogorov-Smirnov test failed to confirm the normality of the sample. Thus, inferential analyses comparing the proportions and averages related to the clinical conditions and the OHRQoL by total scale and subscales of the $\mathrm{CPQ}_{11-14}$, respectively, relative to the subsamples of the subjects covered or not by the SHP were performed by the Mann-Whitney and chi-square tests at a significance level of $5 \%(p<0.05)$.

Crude and adjusted analyses were performed to test the associations between the dependent variable, OHRQoL $\left(\mathrm{CPQ}_{11-14}\right)$, dichotomised by the median $(\mathrm{CPQ} \leq 18$ and $\mathrm{CPQ}>18)$, and the independent sociodemographic, clinical, and SHP access variables, which were dichotomised following Assaf et al., ${ }^{18}$ as previously described. The variables with $p<0.20$ in the crude analyses were tested in the multiple logistic regression model, with the criterion of permanence in the final model set at $\mathrm{p} \leq 0.10$. Although the significance level is routinely set at $5 \%$, a level of significance of $10 \%$ can be accepted in epidemiological studies, especially when there is a consensus of researchers on important variables and findings, with a view to future use of research information for the planning and development of health programs and policies targeting a specific population that would not be identified in an analysis with a smaller error limit. ${ }^{19}$ Statistical tests were performed using the SAS statistical program (SAS Institute Inc. 2011 version 9.4, NC, USA).

\section{Results}

The sample consisted of 319 adolescents. Of the 236 adolescents covered by the SHP for at least two years, 96 participated in the study, representing a response rate of $40.68 \%$. The response rate of nonparticipants in the program was $36.01 \%$. The total sample included $16.61 \%$ rural dwellers and $83.39 \%$ urban, with the majority being female $(59.87 \%)$. The descriptive analyses of the data with the distribution of sociodemographic variables and access to SHP are shown in Table 1.

Considering that a lower $\mathrm{CPQ}_{11-14}$ score is indicative of a better scale result (lower impact of a variable on or impairment in the OHRQoL), a "ceiling" effect (inadequate discrimination in the best $10 \%$ of the
Table 1. Socio-demographic characteristics and access to SHP of the total sample of 12-year-old schoolchildren from Nova Friburgo, RJ, Brazil, 2018.

\begin{tabular}{lcc}
\hline \multirow{2}{*}{ Sociodemographic variables } & \multicolumn{2}{c}{ Sample total $(\mathrm{n}=319)$} \\
\cline { 2 - 3 } $\begin{array}{l}\text { School area } \\
\quad \text { Rural }\end{array}$ & $\mathrm{n}$ \\
$\quad$ Urban & 53 & 16.61 \\
Sex & 266 & 83.39 \\
$\quad$ Female & & \\
$\quad$ Male & 191 & 59.87 \\
Parental schooling & 128 & 40.13 \\
$\quad \leq 8$ years & & \\
$>8$ years & 181 & 69.35 \\
Family income BMW* & 80 & 30.65 \\
$\quad \leq 1.15$ & & \\
$>1.15$ & 119 & 50.85 \\
SHP & 115 & 49.15 \\
Yes & & \\
No & 96 & 30.09 \\
\hline
\end{tabular}

*Median corresponded to 1.15 times the Brazilian minimum wage (BMW) in 2018.

results) was observed when the total score of $\mathrm{CPQ}_{11-14}$ produced a score $\leq 6$, and a "floor" effect (inadequate discrimination in the worst $10 \%$ of the results) when the total score was $\geq 86$. Thus, the ceiling effect was shown by 18 schoolchildren $(5.64 \%)$ who had scores ranging from 0 to 6 , and the floor effect was shown by 6 schoolchildren $(1.88 \%)$ whose scores ranged from 86 to 102 on the total $\mathrm{CPQ}_{11-14}$ scale. In addition, it was found that the prevalence of impacts greater than zero $\left(\mathrm{CPQ}_{11-14}>0\right)$ was $99.69 \%(\mathrm{n}=318)$.

When analysing the clinical characterisation of the oral health conditions of the total sample and of the subsamples contemplated and not contemplated by the SHP, a significant statistical difference was observed between the groups only for gingivitis $(p=0.0373)$ (Table 2). On the other hand, the comparison between the groups covered and not covered by the SHP for the total score and each subscale of the $\mathrm{CPQ}_{11-14}$ showed significant differences for the social welfare subscale $(p=0.0265)$ and for the total scale, calculated as the sum of the four subscales $(p=0.0449)$ (Table 3$)$.

Multivariate analysis showed that the variables of gender $(\mathrm{OR}=1.67,95 \% \mathrm{IC}=1.07-2.63, p=0.0256)$, presence of SHP $(\mathrm{OR}=1.51,95 \% \mathrm{IC}=0.93-2.44$, 
The influence of the Brazilian school health program on the oral-health-related quality of life of adolescents

Table 2. Clinical characterization of the oral health conditions of the total samples and the subsamples covered and not covered by the SHP in the municipality of Nova Friburgo. Nova Friburgo, RJ, Brazil, 2018.

\begin{tabular}{|c|c|c|c|c|c|c|c|c|c|c|}
\hline \multirow{2}{*}{ Clinical condition } & \multicolumn{3}{|c|}{ With SHP $(n=96)$} & \multicolumn{3}{|c|}{ Without SHP $(n=223)$} & \multirow{2}{*}{$p$-value* } & \multicolumn{3}{|c|}{ Total sample $(n=319)$} \\
\hline & Mean & SD & Median & Mean & SD & Median & & Mean & SD & Median \\
\hline Decayed & 0.63 & 1.23 & 0 & 0.45 & 1.18 & 0 & 0.3196 & 0.51 & 1.20 & 0 \\
\hline Missing & 0.01 & 1.10 & 0 & 0.01 & 0.15 & 0 & 0.9842 & 0.01 & 0.14 & 0 \\
\hline Filled & 0.40 & 1.04 & 0 & 0.39 & 1.04 & 0 & 0.9504 & 0.39 & 1.04 & 0 \\
\hline \multirow[t]{2}{*}{ DMFt } & 0.97 & 1.62 & 0 & 0.86 & 1.64 & 0 & 0.6594 & 0.89 & 1.63 & 0 \\
\hline & $\begin{array}{c}\mathrm{n} \text { (condition } \\
\text { presence) }\end{array}$ & $\mathrm{n}$ total & $\%$ & $\begin{array}{c}\mathrm{n} \text { (condition } \\
\text { presence) }\end{array}$ & $\mathrm{n}$ total & $\%$ & $\mathrm{p}$-value** & $\begin{array}{c}\mathrm{n} \text { (condition } \\
\text { presence) }\end{array}$ & $\mathrm{n}$ total & $\%$ \\
\hline Caries-free individuals & 58 & 96 & 60.42 & 141 & 223 & 63.23 & 0.7267 & 199 & 319 & 62.38 \\
\hline Dental trauma (presence) & 16 & 96 & 16.67 & 21 & 223 & 9.42 & 0.0961 & 37 & 319 & 11.60 \\
\hline Dental calculus (presence) & 19 & 92 & 20.65 & 56 & 223 & 25.11 & 0.4842 & 94 & 315 & 29.84 \\
\hline Gingivitis (presence) & 9 & 86 & 10.47 & 48 & 223 & 21.62 & 0.0373 & 57 & 309 & 18.45 \\
\hline
\end{tabular}

Use of the Mann-Whitney *test and chi-square test; ${ }^{* *}$ for comparisons between the groups covered and not covered by the SHP; $\mathrm{p}$-values in bold indicate a difference significant at the $5 \%$ level.

Table 3. Comparison of total means and by subscales of $C P Q_{11.14}$ in the groups covered and not covered by the SHP, in Nova Friburgo-RJ, Brazil, 2018.

\begin{tabular}{lccccccccc}
\hline & \multicolumn{4}{c}{ With SHP } & \multicolumn{3}{c}{ Without SHP } \\
\cline { 2 - 9 } CPQ $_{11-14}$ (variation) & Mean & SD & Median & $\begin{array}{c}\text { Score } \\
\text { variation }\end{array}$ & Mean & SD & Median $\begin{array}{c}\text { Score } \\
\text { variation }\end{array}$ \\
\hline $\begin{array}{l}\text { Total Scale (0-102) (sum of the 4 subscales) } \\
\text { Subscales }\end{array}$ & 17.21 & 14.81 & 12 & $3-78$ & 19.25 & 14.76 & 16 & $0-102$ & 0.0449 \\
$\quad$ Oral symptoms (0-24) & 5.49 & 3.33 & 5 & $0-16$ & 6.05 & 3.49 & 6 & $0-18$ & 0.1365 \\
$\quad$ Functional Limitations (0-36) & 4.75 & 4.86 & 4 & $0-23$ & 4.99 & 5.16 & 4 & $0-35$ & 0.8071 \\
$\quad$ Emotional well-being (0-36) & 6.12 & 7.10 & 4 & $0-27$ & 6.84 & 7.09 & 5 & $0-36$ & 0.1526 \\
$\quad$ Social well-being (0-16) & 0.88 & 1.84 & 0 & $0-12$ & 1.32 & 2.13 & 0 & $0-12$ & 0.0265 \\
\hline
\end{tabular}

Use of the Mann-Whitney test for comparisons of means between the groups contemplated or not by the program; $p$-values in bold indicate a difference significant at the $5 \%$ level.

$\mathrm{p}=0.0953)$, and gingivitis $(\mathrm{OR}=1.63,95 \% \mathrm{IC}=0.91-2.92$, $\mathrm{p}=0.1028$ ) were associated with OHRQoL. In the adjusted analysis, it was found that female adolescents were 1.74 times more likely to present a worse OHRQoL $(\mathrm{OR}=1.74,95 \% \mathrm{IC}=1.10-2.77, \mathrm{p}=0.0183)$ than males. In addition, non-SHP subjects were 1.56 times more likely to have a poor OHRQoL $(\mathrm{OR}=1.56,95 \% \mathrm{IC}=0.94-2.59$, $\mathrm{p}=0.0873$ ) than the program participants (Table 4).

\section{Discussion}

Health promotion programs have positive effects on oral health and related quality of life. ${ }^{3,8,9,10,11}$ Thus, the hypothesis that the SHP positively affects OHRQoL has been confirmed as well as clinical improvements related to decreasing the prevalence of gingivitis in this group.
The actions of the program that may have influenced OHRQoL were those of an educational nature focused on healthy eating (reduction of sugar consumption) and mechanical control of dental biofilm, intended to encourage protagonism and the empowerment of adolescents in self-care. ${ }^{1,3}$

However, it is clear that the program had little influence specifically regarding reductions of caries and trauma as well as a greater impact on the OHRQoL itself. Some factors may be related to this result, such as the frequency of program actions, often semiannual, and even deficiencies or difficulties in the development of the program within the scope of health promotion. Understanding health promotion as a strategy for reformulating health practices implies the development of intersectoral and multidimensional actions focused on common risk factors and the 
Table 4. Crude and adjusted analyzes of $C P Q_{11-14} / O H R Q o L$ (dependent variable) in relation to sociodemographic, clinical and SHP access variables of Nova de Friburgo, RJ, Brazil, 2018.

\begin{tabular}{|c|c|c|c|c|c|c|c|c|c|c|c|}
\hline \multirow{3}{*}{ Independent variables } & \multirow{3}{*}{ Total } & \multirow{2}{*}{\multicolumn{2}{|c|}{$\begin{array}{c}\text { Better OHRQoL } \\
(\mathrm{CPQ} \leq 18)\end{array}$}} & \multirow{2}{*}{\multicolumn{2}{|c|}{$\begin{array}{c}\text { Worse OHRQoL } \\
\qquad(\mathrm{CPQ}>18)\end{array}$}} & \multirow{3}{*}{ OR Bruto } & \multirow{3}{*}{$95 \% \mid C$} & \multirow{3}{*}{$p$-value } & \multirow{3}{*}{$\begin{array}{c}\text { OR } \\
\text { adjusted }\end{array}$} & \multirow{3}{*}{$95 \% \mid C$} & \multirow{3}{*}{$p$-value } \\
\hline & & & & & & & & & & & \\
\hline & & $n$ & $\%$ & $\mathrm{n}$ & $\%$ & & & & & & \\
\hline \multicolumn{12}{|l|}{ Sex } \\
\hline Female & 191 & 86 & 45.03 & 105 & 54.97 & 1.67 & $1.07-2.63$ & 0.0256 & 1.74 & $1.10-2.77$ & 0.0183 \\
\hline Male & 128 & 74 & 57.81 & 54 & 42.19 & ref & & & ref & & \\
\hline \multicolumn{12}{|l|}{ School area } \\
\hline Rural & 53 & 31 & 58.49 & 22 & 41.51 & ref & & & -- & -- & -- \\
\hline Urban & 266 & 129 & 48.50 & 137 & 51.50 & 1.50 & $0.82-2.72$ & 0.1857 & & & \\
\hline \multicolumn{12}{|l|}{ SHP } \\
\hline Yes & 96 & 55 & 57.29 & 41 & 42.71 & ref & & & ref & & \\
\hline No & 223 & 105 & 47.09 & 118 & 52.91 & 1.51 & $0.93-2.44$ & 0.0953 & 1.56 & $0.94-2.59$ & 0.0873 \\
\hline \multicolumn{12}{|l|}{ DMFt } \\
\hline$\leq 0$ & 196 & 100 & 51.02 & 96 & 48.98 & ref & & & -- & -- & -- \\
\hline$>0$ & 123 & 60 & 48.78 & 63 & 51.22 & 1.09 & $0.70-1.72$ & 0.6970 & & & \\
\hline \multicolumn{12}{|l|}{ Dental trauma (free) } \\
\hline No & 37 & 17 & 45.95 & 20 & 54.05 & 121 & $0.61-2.41$ & 0.5870 & -- & -- & -- \\
\hline Yes & 282 & 143 & 50.71 & 139 & 49.29 & ref & & & & & \\
\hline \multicolumn{12}{|l|}{ Gingivitis (free) } \\
\hline Yes & 252 & 132 & 52.38 & 120 & 47.62 & ref & & & -- & -- & -- \\
\hline No & 57 & 23 & 40.35 & 34 & 59.65 & 1.63 & $0.91-2.92$ & 0.1028 & & & \\
\hline \multicolumn{12}{|l|}{ Parental schooling } \\
\hline$\leq 8$ years & 65 & 34 & 52.31 & 31 & 47.69 & ref & & & -- & -- & -- \\
\hline$>8$ years & 196 & 94 & 47.96 & 102 & 52.04 & 1.19 & $0.68-2.09$ & 0.5437 & & & \\
\hline \multicolumn{12}{|l|}{ Family income (BMW)* } \\
\hline$\leq 1.15$ & 119 & 55 & 46.22 & 64 & 53.78 & 1.23 & $0.73-2.05$ & 0.4371 & -- & -- & -- \\
\hline$>1.15$ & 115 & 59 & 51.30 & 56 & 48.70 & ref & & & & & \\
\hline
\end{tabular}

$\mathrm{CPQ}>18$ is the reference level of the dependent variable (worse OHRQoL); BMW: Median corresponded to 1.15 times the Brazilian minimum wage (BMW) in 2018; SHP: School Health Program; OR: Odds Ratio; Cl: Confidence Interval.

main health determinants, ${ }^{1,2}$ which in practice was not always observed in the SHP developed in the municipality. Thus, it should be emphasised that educational interventions in oral health apart from other health actions and with fragmented approaches that separate the oral cavity from general health have been criticised because they are limited in ensuring a permanent transformation in individuals, or even in reducing health inequalities., ${ }^{2,18}$

In addition to the factors mentioned above, it is possible to highlight the absence of a strategy of continuing education in health between the teachers and the primary care professionals that will be a part of adolescents' day-to-day life. Thus, it is necessary for the students to be motivated and the teachers trained so that the concept of oral health promotion is an integral part of school life, ensuring that the information and healthy habits acquired are applied continuously. ${ }^{1,2,3}$ However, it should also be noted that because this is a cross-sectional study, it already has restrictions inherent to its design of measuring clinical or subjective impacts not shared by other designs such as interventional and longitudinal follow-up clinical studies.

Adolescence is accompanied by many physiological, psychological, and hormonal turbulence changes, and there are behavioural differences between female and male adolescents. A poorer OHRQoL was found in female subjects, ${ }^{18,20}$ which may be due to the different self-perceptions of boys and girls, especially at the beginning of the profound transformations accompanying 
adolescence, such as early maturation and intense hormonal changes, the need to be accepted in society, appearance, aesthetics, vanity, and disturbances of their self-image among girls. ${ }^{21}$

Regarding the limitations of the study, there was considerable non-adherence of participants, especially those belonging to schools not covered by the SHP. This may be related to factors such as the absence of the adolescent on the day of the examination and incomplete or inadequate completion of ethical documents and research instruments. However, from the information obtained by the school leaders, it was observed that sociodemographically there was a similarity between the participants and non-participants of the study. In addition, the fact that the study had a cross-sectional design with a non-probabilistic sample, and the presence of other possible biases during the data collection phase (e.g., variable natural lighting conditions during exams and different school routines) may also constitute study limitations.

However, the study's strong points are the natural scenario in which it was developed and its adequate internal validity, with the control of the whole research process through a pilot study and calibration of the examiners, satisfactory results (internal consistency, test-retest, and construct validity), and control at the stage of data collection and analysis. Regarding this last aspect, the multiple analysis allowed us to control important conflicting factors, such as those of a sociodemographic nature, leading to a possible reduction in this type of bias. In addition, this study is original, since few cross-sectional studies $^{8,10,11}$ have attempted to ascertain the hypothesis developed in this research, especially in relation to an institutionalised health promotion program at the federal level in Brazil. Therefore, it can be considered highly relevance as an evaluative measure that will benefit health managers in replanning actions and strategies for the improvement of the program and consequent improvements in the oral health levels and quality of life related to oral health in this age group. However, follow-up studies are still necessary to verify the continued effectiveness of this Brazilian SHP in improving the oral health levels and quality of life of adolescents.

\section{Conclusion}

SHP positively influenced the OHRQoL of adolescents. This study is of great importance to public health and to clinicians in view of the relevance of health-promoting practices in the control and reduction of oral diseases and in the improvement of individual quality of life.

\section{Acknowledgments}

The authors of this study are grateful for the financial support received from CAPES as well as the Municipal and State Education Offices, directors of public schools, and all adolescents and their parents who participated in this work during 2018.

\section{References}

1. Ministério da Saúde (BR). Secretaria de Atenção à Saúde. Departamento de Atenção Básica. Saúde na escola. Brasília, DF: Ministério da Saúde; 2009 [cited: 2018 July 20]. Available from: http://189.28.128.100/dab/docs/publicacoes/cadernos_ab/abcad24.pdf

2. Moysés ST, Moysés SJ, Watt RG, Sheiham A. Associations between health promoting schools' policies and indicators of oral health in Brazil. Health Promot Int. 2003 Sep;18(3):209-18. https://doi.org/10.1093/heapro/dag016

3. Stein C, Santos NM, Hilgert JB, Hugo FN. Effectiveness of oral health education on oral hygiene and dental caries in schoolchildren: systematic review and meta-analysis. Community Dent Oral Epidemiol. 2018 Feb;46(1):30-7. https://doi.org/10.1111/cdoe.12325

4. Kumar S, Kroon J, Lalloo R. A systematic review of the impact of parental socio-economic status and home environment characteristics on children's oral health related quality of life. Health Qual Life Outcomes. 2014 Mar;12(1):41. https://doi.org/10.1186/1477-7525-12-41

5. Barbosa TS, Gavião MB. Oral health-related quality of life in children: part II. Effects of clinical oral health status. A systematic review. Int J Dent Hyg. 2008 May;6(2):100-7. https://doi.org/10.1111/j.1601-5037.2008.00293.x

6. Pakpour AH, Lin C-Y, Kumar S, Fridlund B, Jansson H. Predictors of oral health-related quality of life in Iranian adolescents: a prospective study. J Invest Clin Dent. 2017;e12264. https://doi.org/10.1111/jicd.12264 
Lattanz AP, Marques APF, Silveira FM, Valente MIB, Antunes LA, Cortellazzi KL, et al.

7. Fonseca RC, Antunes JL, Cascaes AM, Bomfim RA. Analysis of the combined risk of oral problems in the oral health-related quality of life of Brazilian adolescents: multilevel approach. Clin Oral Investig. 2020 Feb;24(2):857-866. https://doi.org/10.1007/s00784-019-02976-z

8. Amália R, Schaub RM, Stewart RE, Widyanti N, Groothoff JW. Impact of school-based dental program performance on the oral health-related quality of life in children. J Investig Clin Dent. 2017 Feb;8(1):e12179. https://doi.org/10.1111/jicd.12179

9. Amato JN, Barbosa TS, Kobayashi FY, Gavião MB. Changes in the oral-health-related quality of life of Brazilian children after an educational preventive programme: an 1-month longitudinal evaluation. Int J Dent Hyg. 2014 Aug;12(3):226-33. https://doi.org/10.1111/idh.12075

10. Carvalho JC, Rebelo MA, Vettore MV. The relationship between oral health education and quality of life in adolescents. Int J Paediatr Dent. 2013 Jul;23(4):286-96. https://doi.org/10.1111/ipd.12006

11. Mashoto KO, Astrøm AN, Skeie MS, Masalu JR. Changes in the quality of life of Tanzanian school children after treatment interventions using the Child-OIDP. Eur J Oral Sci. 2010 Dec;118(6):626-34. https://doi.org/10.1111/i.1600-0722.2010.00776.x

12. Elm E, Altman DG, Egger M, Pocock SJ, Gøtzsche PC, Vandenbroucke JP. The Strengthening the Reporting of Observational Studies in Epidemiology (STROBE) statement: guidelines for reporting observational studies. J Clin Epidemiol. 2008 Apr;61(4):344-9. https://doi.org/10.1016/i.jclinepi.2007.11.008

13. Instituto Brasileiro de Geografia e Estatística - IBGE. Brasil / Rio de Janeiro / Nova Friburgo: panorama. Rio de Janeiro: Instituto Brasileiro de Geografia e Estatística; 2018 [cited: 2018 Apr 19]. Available from: https://cidades.ibge.gov.br/brasil/ri/nova-friburgo/panorama

14. Marques AP, Ferraz A, Lima Netto LG, Ditterich RG, Silveira FM, Caldo-Teixeira AS, et al. Access to fluoridated water: an overview since its implantation in a city of Rio de Janeiro State, Brazil. Rev Bras Odontol. 2018;75:1124. https://doi.org/10.18363/rbo.v75.2018.e1124

15. Ministério da Saúde (BR). Secretaria de Atenção à Saúde. Departamento de Atenção Básica. Projeto SB Brasil 2010: Pesquisa nacional em saúde bucal: resultados principais. relatório. Brasília, DF: Ministério da Saúde; 2011 [cited: 2018 May 10]. Available from: http://bvsms.saude.gov.br/bvs/publicacoes/SBBrasil_2010.pdf

16. Barbosa TS, Tureli MC, Gavião MB. Validity and reliability of the Child Perceptions Questionnaires applied in Brazilian children. BMC Oral Health. 2009 May;9(9):13. https://doi.org/10.1186/1472-6831-9-13

17. World Health Organization - WHO. Oral health surveys, basic methods. 5th ed. Geneva: World Health Organization; 2013.

18. Assaf AV, Caldo-Teixeira AS, Silveira FM, Valente MI, Ditterich RG, Barcelos R. Dental caries in inland Brazilian adolescents and its relationship with social determinants. Braz J Oral Sci. 2014;13(2):133-9. https://doi.org/10.1590/1677-3225v13n2a11

19. Smith GC, Seaman SR, Wood AM, Royston P, White IR. Correcting for optimistic prediction in small data sets. Am J Epidemiol. 2014 Aug;180(3):318-24. https://doi.org/10.1093/aje/kwul40

20. Sun L, Wong HM, McGrath CP. The factors that influence oral health-related quality of life in 15 -year-old children. Health Qual Life Outcomes. 2018 Jan;16(1):19. https://doi.org/10.1186/s12955-018-0847-5

21. Walker DM, Bell MR, Flores C, Gulley JM, Willing J, Paul MJ. Adolescence and reward: making sense of neural and behavioral changes amid the chaos. J Neurosci. 2017 Nov;37(45):10855-10866. https://doi.org/10.1523/JNEUROSCI.1834-17.2017 